\title{
The Interaction of Helicobacter pylori with TFF1 and Its Role in Mediating the Tropism of the Bacteria Within the Stomach
}

\author{
Marguerite Clyne ${ }^{1, *}$ and Felicity E. B. May ${ }^{2}$ \\ 1 School of Medicine and Conway Institute, University College Dublin, Belfield, 4, D04 V1W8 Dublin, Ireland \\ 2 Northern Institute for Cancer Research, Faculty of Medical Sciences, University of Newcastle upon Tyne, \\ Newcastle-upon-Tyne NE2 4HH, UK \\ * Correspondence: marguerite.clyne@ucd.ie; Tel.: +353-1-7166619
}

Received: 26 July 2019; Accepted: 6 September 2019; Published: 7 September 2019

\begin{abstract}
Helicobacter pylori colonises the human stomach and has tropism for the gastric mucin, MUC5AC. The majority of organisms live in the adherent mucus layer within their preferred location, close to the epithelial surface where the $\mathrm{pH}$ is near neutral. Trefoil factor 1 (TFF1) is a small trefoil protein co-expressed with the gastric mucin MUC5AC in surface foveolar cells and co-secreted with MUC5AC into gastric mucus. Helicobacter pylori binds with greater avidity to TFF1 dimer, which is present in gastric mucus, than to TFF1 monomer. Binding of $H$. pylori to TFF1 is mediated by the core oligosaccharide subunit of $H$. pylori lipopolysaccharide at $\mathrm{pH}$ 5.0-6.0. Treatment of H. pylori lipopolysaccharide with mannosidase or glucosidase inhibits its interaction with TFF1. Both TFF1 and $H$. pylori have a propensity for binding to mucins with terminal non-reducing $\alpha$ - or $\beta$-linked $\mathrm{N}$-acetyl-D-glucosamine or $\alpha-(2,3)$ linked sialic acid or Gal-3-SO ${ }_{4}{ }^{2-}$. These findings are strong evidence that TFF1 has carbohydrate-binding properties that may involve a conserved patch of aromatic hydrophobic residues on the surface of its trefoil domain. The $\mathrm{pH}$-dependent lectin properties of TFF1 may serve to locate $H$. pylori deep in the gastric mucus layer close to the epithelium rather than at the epithelial surface. This restricted localisation could limit the interaction of H. pylori with epithelial cells and the subsequent host signalling events that promote inflammation.
\end{abstract}

Keywords: Helicobacter pylori; TFF1; lectin; MUC5AC; lipopolysacchairde

\section{Introduction}

\subsection{Site-Specific Tropism of Helicobacter Pylori in the Stomach}

Approximately $60 \%$ of the global human population is infected with Helicobacter pylori which means that $H$. pylori is one of the commonest pathogens of mankind. The prevalence of infection ranges from $70 \%$ in Africa to approximately 35\% in North America and Western Europe or 25\% in Australia and New Zealand [1]. Infection with H. pylori clusters in families [2]. Individuals are normally infected in early life [3] and infection persists for the individual's lifetime unless eradicated with antimicrobials. Helicobacter pylori colonises the gastric mucosa and induces a complex inflammatory response that causes chronic antral gastritis in both adults and children $[4,5]$. While the majority of those infected are asymptomatic, up to $10 \%$ develop duodenal ulceration. Helicobacter pylori is classed as a group I carcinogen because infection is associated with the development of gastric cancer $[6,7]$ of which the vast majority of cases are of non-cardia gastric cancer [8].

One of the most striking characteristics of $H$. pylori is its species and tissue specificity. This microorganism only infects humans or non-human primates and the stomach is the only reservoir that $\mathrm{H}$. pylori can be consistently isolated from. Although the organism can be found deep in 
the gastric glands $[9,10]$ and a recent study in a murine model suggested that this $H$. pylori population may provide a long-term reservoir [11], the majority of bacteria are located in the gastric pits and in the mucus overlying the epithelial cells with only a small percentage attached to the epithelial cells $[12,13]$. Helicobacter pylori are found in the duodenum and oesophagus but only at sites of gastric metaplasia [14] which emphasises their specific tropism for the gastric mucosal surface.

Helicobacter pylori has been shown to colocalise with the mucin MUC5AC that is secreted by normal gastric surface mucosal cells $[15,16]$. Helicobacter pylori does not adhere to intestinal metaplastic cells in the stomach that have a complete intestinal phenotype and express the mucin MUC2 but does adhere to metaplastic cells that have an incomplete intestinal phenotype and retain expression of MUC5AC [17,18]. Further, MUC5AC is expressed in the areas of gastric metaplasia in the duodenum and oesophagus that $H$. pylori can colonise [14]. The above findings provide strong evidence that MUC5AC, or a molecule that is co-expressed with MUC5AC, mediates the sequestration of $H$. pylori within the adherent gastric mucus gel layer.

An adherent mucus gel layer lines the stomach in its entirety [19]. This adherent mucus layer is thicker than adherent mucus layers elsewhere in the gastrointestinal tract, presumably because it is required to protect the gastric epithelium from the high hydrochloric acid concentration, low $\mathrm{pH}$ environment of the gastric lumen, and from digestion by pepsin. There is a hydrogen ion concentration gradient across the adherent mucus layer from $1.1 \times 10^{-4} \mathrm{M}, \mathrm{pH} 6.96$ at the junction between the gastric epithelium and the adherent mucus, to $5.6 \times 10^{-3} \mathrm{M}, \mathrm{pH} 2.25$ in the lumen [20]. Bicarbonate secretion into the mucus layer by the epithelium neutralises the hydrogen ions that diffuse from the gastric lumen into the mucus layer to generate the $\mathrm{pH}$ gradient [20].

The adherent mucus gel layer has been reported to have a multi-laminated structure formed by overlapping layers of mucins [13], MUC5AC, derived from the gastric surface mucus-secretory cells and MUC6 from the gland mucus-secretory cells. Helicobacter pylori colonises preferentially within the MUC5AC layer of mucin [13]. Despite causing chronic infection in the stomach, H. pylori is not an acidophile [21] and infection of experimental animals demonstrates that it colonises a narrow anatomical niche of the adherent mucus gel layer within $25 \mu \mathrm{m}$ of the epithelium [22], at which the $\mathrm{pH}$ is near neutral. Helicobacter pylori has been reported to interact with MUC5AC via outer membrane protein adhesins and O-linked oligosaccharides displayed on the mucin [23-26].

\subsection{Site-Specific Localisation of Trefoil Proteins and Co-Expression with Mucins in the Gastrointestinal Tract}

The trefoil factor family proteins, TFF1, TFF2 and TFF3, are small secreted proteins thought to play a role in mucosal protection and repair and to help maintain mucus integrity possibly by cross-linking mucins to aid in the formation of stable mucus gel layers [27-29]. Trefoil proteins contain trefoil domains that are characterised by several conserved amino acid residues. Six cysteine residues, with conserved spacing form three inter-domain disulphide bonds with common cysteine pairing [27,29]. Both TFF1 and TFF3 have a single trefoil domain and an extra-trefoil domain seventh cysteine three residues from each of their carboxy-termini that is available to form inter-molecular covalent bonds [29-31]. TFF2 contains two trefoil domains and two extra-trefoil domain cysteine residues that form a disulphide bond between its amino and carboxy termini [29]. TFF1, TFF2 and TFF3 were identified originally as an oestrogen-responsive gene product in human breast cancer cells [32,33], a constituent of porcine pancreatic protein preparations [34] and a rat intestinal protein [35], respectively. It is recognised now that TFF1, TFF2 and TFF3 are synthesised and secreted predominantly by normal secretory epithelia $[27,36]$.

TFF3 is expressed most widely, followed by TFF1 with expression of TFF2 being more restricted [27,36]. For example, TFF1 and TFF3 are present in the respiratory system with strong immunoreaction for TFF3 in the goblet cells of bronchi [37]. Both proteins are also expressed in normal breast epithelial cells $[38,39]$. TFF1 and TFF3 are detected in the male and female reproductive tracts with changes to endometrial TFF3 expression coincident with the implantation window. Expressed frequently alongside mucins, the idea evolved that individual trefoil factors are more likely to be 
co-expressed with individual mucins. It is in the gastrointestinal tract that trefoil factor expression and co-localisation with mucins has been studied most, especially in hollow organs though their expression in the endocrine pancreas is recognised. Both TFF1 and TFF3 are produced in the minor salivary glands in the mouth and in the submucosal glands in the oesophagus [40]. TFF1 and TFF2 are expressed in the stomach and all three trefoil proteins are expressed in the duodenum [41]. TFF1 is detected in Brunner's glands of the duodenum and in some goblet cells, TFF2 is expressed in large amounts exclusively in Brunner's glands of the duodenum and TFF3 in large amounts exclusively in all goblet cells of the duodenum. Thereafter, in the jejunum, ileum, colon and rectum, expression of TFF3 predominates; it is present in all goblet cells alongside the secreted mucin, MUC2, whereas TFF1 is expressed in only a subset of goblet cells. As well as being secreted into the gastrointestinal lumen, TFF1 is synthesised in gastric and intestinal, and TFF3 in intestinal, enteroendocrine or neuroendocrine cells for secretion into the lamina propria to exert paracrine actions or thence, after release into the circulation, for transport through the vasculature to exert endocrine actions [40].

Within the stomach, TFF1 is expressed in large amounts in the mucus secretory foveolar cells throughout the stomach and is detected packaged alongside the secreted mucin, MUC5AC, in mucin granules of the apical mucous secretory vesicles ready for release into the adherent mucus layer [42] (Figure 1A,B). The membrane mucin, MUC1 is co-expressed also by the gastric surface mucous secretory cells. TFF2 is detected in the mucus neck cells of the gastric fundus and body in the basal glands in the antrum and pylorus [41,43]. It co-localises within these cells with the secreted mucin, MUC6. TFF3 is not expressed by normal human stomach $[40,44]$.
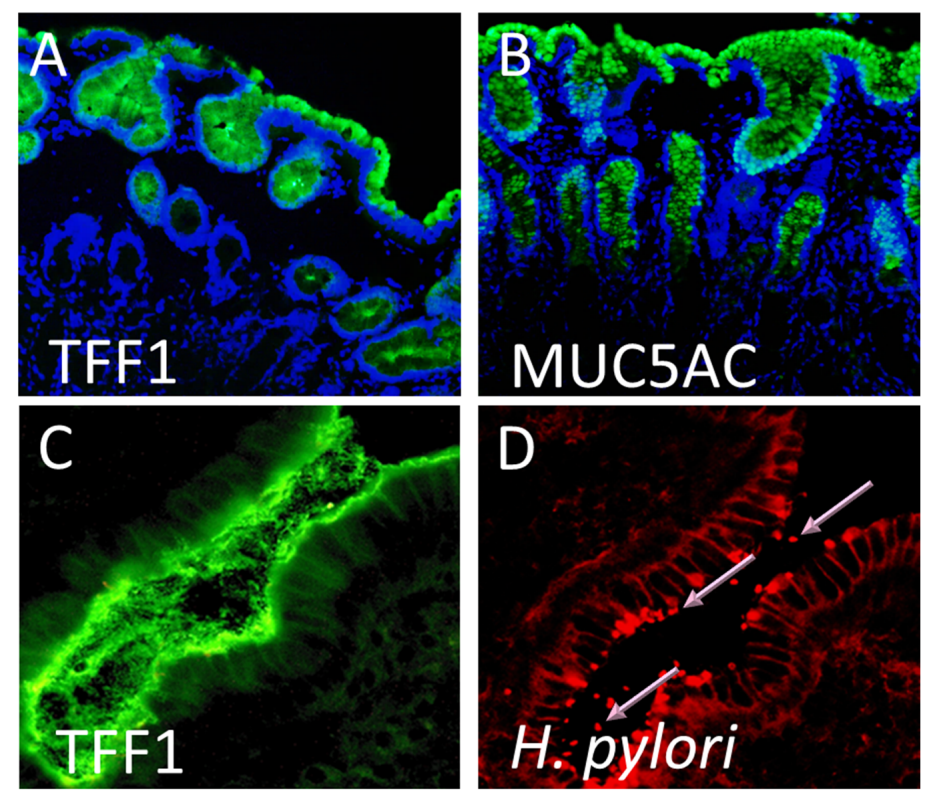

Figure 1. Trefoil factor 1 (TFF1), the mucin MUC5AC, and Helicobacter pylori are found at the same sites in the human stomach. Formalin-fixed gastric mucosal tissue from $H$. pylori-negative individuals were immunofluorescently stained using specific antibodies against (A) TFF1 and (B) MUC5AC. Both TFF1 (green) and MUC5AC (green) staining occurred on gastric surface foveolar cells and in the glands. Cell nuclei were counter stained with DAPI (blue). Original magnification 100×. A frozen section of $H$. pylori infected antral gastric biopsy tissue was immunofluorescently stained using specific antibodies against (C) TFF1 and (D) H. pylori. Both TFF1 (green) and H. pylori (red) were detected at the epithelial surface and in the overlying gastric mucus. Pink arrows indicate $H$. pylori organisms staining bright red. The same field is shown in (C,D). Original magnification $200 \times$.

The adherent mucus gel layer was destroyed by conventional fixation prior to histology or immunohistochemistry. Examination of carefully preserved cryosections allowed us to demonstrate high concentrations of TFF1 throughout the adherent mucus layer with apparent concentration in the 
lower half of the mucus layer next to the epithelial cells [45]. Thus, the close association between TFF1 and MUC5AC detected in mucus granules of foveolar cells [42] was maintained following secretion into the adherent mucus layer. However, although TFF1 was present throughout the mucus layer, it was concentrated at the higher- $\mathrm{pH}$ end of the $\mathrm{pH}$ gradient proximal to the epithelial surface.

Three molecular forms of TFF1 were detected in normal gastric mucosa and adherent mucus, a $6.67 \mathrm{kDa}$ monomer, a $13.33 \mathrm{kDa}$ homodimer and an $25 \mathrm{kDa}$ heterodimer [45] with another secreted protein, the $18.3 \mathrm{kDa}$ TFIZ1 [46] encoded by GKN2 [47]. Early analysis by caesium chloride density gradient centrifugation demonstrated that the TFF1 homodimer, and to a lesser extent the monomer, banded with mucin glycoproteins [45]. The association between TFF1 homodimer and mucins resisted disruption with guanidine hydrochloride consistent with the interaction being non-ionic, possibly hydrophobic in nature. Analysis under physiological conditions demonstrated that the endogenous gastric TFF1 homodimer is associated with MUC5AC but not MUC6 because it co-elutes with the former but not the latter after fractionation by native gel filtration [42]. This association between TFF1 dimer and MUC5AC was confirmed by immunoprecipitation with antibodies against each protein followed by non-reducing western transfer analysis and detection with antibodies against the other. An involvement of divalent cations in the interaction between MUC5AC and TFF1 homodimer was indicated by disruption of the interaction by incubation with EGTA and confirmed by the increased association obtained in the presence of $\mathrm{Ca}^{2+}$.

The co-expression of TFF1 with the gastric mucin MUC5AC and the co-localisation of H. pylori with both TFF1 and MUC5AC (Figure 1) led us to hypothesise that an interaction between H. pylori and TFF1 could explain the distinct tropism that the organism has for the gastric mucosa.

\section{Helicobacter pylori Interacts with the Dimeric Form of TFF1}

To test the above hypothesis, we investigated if there is an interaction between $H$. pylori and TFF1. Co-localisation of $H$. pylori and TFF1 was shown by immunofluorescence in parallel sections of gastric biopsies from H. pylori-infected individuals [48]. A direct interaction between H. pylori and recombinant TFF1 dimer coated onto latex beads was demonstrated in a flow cytometric adherence assay. Five H. pylori strains, two strains of Campylobacter jejuni and Escherichia coli stain HB101 were tested. All five strains of H. pylori bound to TFF1-coated beads but no binding was detected for the two C. jejuni strains or for E. coli. Binding of $H$. pylori to the beads was inhibited by pre-incubation of the TFF1 dimer-coated beads with a TFF1 monoclonal antibody [48]. Furthermore, the interaction of $H$. pylori with beads coated with the monomeric form of TFF1 was negligible.

The interaction of $H$. pylori with TFF1 dimer was confirmed by surface plasmon resonance (SPR) [48], which allows real-time monitoring of molecular interactions at a sensor surface [49]. We used a CM5 sensor chip which is a glass slide with a thin layer of gold on one side covered with a covalently bound carboxymethylated (CM) dextran matrix attached by a hydroxyalkyl thiol linker layer. Light energy generated when there is an interaction with the gold film generates SPR and changes resulting from binding interactions between ligands and proteins immobilized on the chip can be monitored. We immobilised TFF1 to the sensor chip and allowed H. pylori to be passed over the surface. Helicobacter pylori interacted specifically with TFF1 dimer bound to the sensor chip and not with an uncoated dextran chip. The $\mathrm{IC}_{50}$ for inhibition of $H$. pylori binding to TFF1 dimer by TFF1 in solution was $30.5 \mathrm{ng} / \mathrm{mL}$ and $1.56 \mu \mathrm{g} / \mathrm{mL}$ TFF1 abolished binding completely which demonstrates that the H. pylori interaction was with TFF1. An early study reported that TFF1 and TFF3 could be detected on the surface of Staphylococcus aureus organisms present in the lumen of infected airways and in sputum from cystic fibrosis patients based upon co-localisation of immunofluorescence [37], but H. pylori is the only bacterium that has been shown to interact physically with a member of the trefoil factor family of proteins. The identification of TFF1 as a binding partner for H. pylori might play a role in enabling this organism to persist in gastric mucus and cause chronic infection. It also opens up the possibility that TFF1 or TFF1 analogues might be used to either treat or prevent infection with H. pylori. 


\section{The Interaction of $H$. pylori with TFF1 is Mediated via Glycans Present on the Core Oligosaccharide Region of Lipopolysaccharide}

The demonstration that $H$. pylori interact specifically with TFF1 raised the question of how this interaction might occur. Helicobacter pylori is a $3 \mu \mathrm{m}$ long helix-shaped rod-like bacterium of $0.5 \mu \mathrm{m}$ diameter. Its motility is conferred by 4 to 6 sheathed monopolar flagella composed of two flagellin subunits, FLaA and FLaB [50]. The flagellar sheath is a continuation of the bacterial phospholipid outer membrane and is thought to protect the flagella filament from gastric acid. The outer-membrane contains, as do all Gram-negative bacteria, lipopolysacharide (LPS) (Figure 2). Helicobacter pylori LPS comprises lipid A, which anchors it in the phospholipid outer membrane, a core oligosaccharide, which together with lipid A maintains the integrity of the outer membrane and the O-antigen, characterised by fucosylated and nonfucosylated $\mathrm{N}$-acetyllactosamine saccharide units connected to the core and extending on the outer surface of the bacteria [51-54]. Lipid A of H. pylori has a unique structure; it is less acylated and less phosphorylated than lipid A from other bacteria which reduces its endotoxic activity [55] and increases its resistance to cationic microbial peptides [56]. The O-antigen can mimic the host Lewis antigens [53] which allows H. pylori to evade immune recognition [57]. Lipopolysaccharide that contains lipid A and the inner and outer core oligosaccharides are generally referred to as rough-form LPS (RF-LPS), whereas the complete LPS capped with the O-antigen is called smooth-form LPS (SF-LPS) (Figure 2). A number of outer membrane proteins of $H$. pylori have been identified as adhesins $[23,25,26]$ as has the Lewis $\times\left(\operatorname{Le}^{\mathrm{x}}\right)$ blood group epitope that is part of the LPS O-antigen [58]. The outer membrane of $H$. pylori might plausibly interact with TFF1 via one or more of these bacterial cell surface molecules.

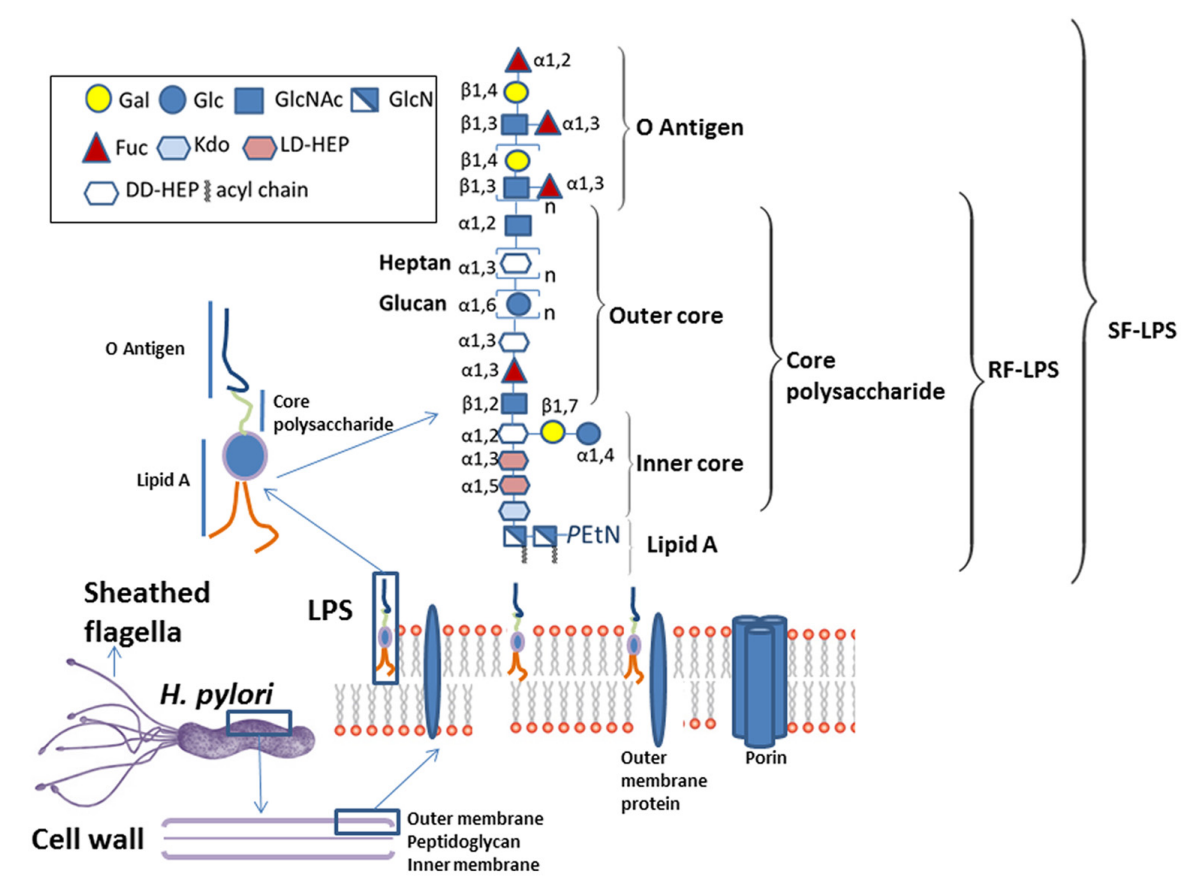

Figure 2. Components of the surface of $H$. pylori that have the potential to interact with host molecules include the flagella, outer membrane proteins and lipopolysaccharide (LPS). The location of H. pylori flagella, the structure of the Gram-negative bacterial cell wall together with the detailed composition of H. pylori LPS as described by Li et al [59] are shown.

The specificity of possible interactions was investigated initially by SPR [60]. The TFF1 dimer inhibited binding of $H$. pylori to a TFF1-coated dextran chip; TFF3 dimer was ten-fold less potent and TFF2 was unable to displace the bacterium. Thus, interaction of $H$. pylori is specific for the TFF1 dimer. TFF1 dimer but not TFF1 monomer interacted with an $\sim 6 \mathrm{kDa}$ molecule from $H$. pylori lysates after their separation by denaturing polyacrylamide gel electrophoresis and transfer to polyvinylidene 
difluoride (PVDF) membrane. Subsequent analysis of $H$. pylori fractions demonstrated that the $\sim 6 \mathrm{kDa}$ molecule is present in the bacterium's outer membrane and flagella but not in its inner membrane. This molecule interacted with Alcian blue which stains glycosylated molecules consistent with the molecule containing glycan. Pre-incubation of $H$. pylori lysates with proteinase $\mathrm{K}$ did not affect interaction of TFF1 with the $\sim 6 \mathrm{kDa}$ molecule nor its detection with Alcian blue but pre-incubation with sodium metaperiodate prevented the interaction with TFF1 and detection with Alcian blue [60], consistent with the interaction being between TFF1 dimer and a H. pylori saccharide. These data strongly suggested that LPS on the surface of H. pylori mediates the interaction of H. pylori with TFF1.

Alcian blue detects also a prominent $\sim 6 \mathrm{kDa}$ molecule corresponding to RF-LPS and less well two larger molecules shown to contain O-antigens in purified H. pylori LPS after separation by denaturing gel electrophoresis. Recombinant TFF1 dimer interacted with purified H. pylori RF-LPS, specifically with the $\sim 6 \mathrm{kDa}$ molecule, but not with higher molecular mass SF-LPS after electrophoresis and transfer to PVDF membrane. An interaction was confirmed by altered non-denaturing gel electrophoretic mobility of TFF1 after incubation with RF-LPS and by detection of binding of TFF1 dimer to an H. pylori RF-LPS-coated chip by SPR. The interaction was inhibited by pre-incubation of $H$. pylori RF-LPS with mannosidase and glucosidase whereas incubation with galactosidase and fucosidase was ineffective. Pre-incubation of TFF1 with mannose and glucose together but not with either alone reduced the interaction between TFF1 dimer and H. pylori RF-LPS demonstrating that the interaction involves probably both mannose and glucose [60].

An early study of the core oligosaccharide of H. pylori indicated that it contains glucose and mannose [61]. A more recent study compared LPS of two well-characterised H. pylori strains [62], the weakly inflammatory, mouse-adapted strain SS1 [63] and the potent inflammatory H. pylori Type I strain G27 [64]. LPS was extracted by the hot-phenol water method and the aqueous and phenol layers analysed by gas chromatography-mass spectrometry. Significant amounts of xylose, mannose, galactose, glucose, heptose, and N-acetylglucosamine were detected in LPS fractions from both strains but the abundance of the different monosaccharides varied between the strains and their fractions; mannose was more abundant in strain G27 than in strain SS1 [62]. It was suggested that the failure of other studies to show the presence of mannose in H. pylori LPS [50] is due to the differences in the culture conditions of the bacteria [55].

Comparison of the interactions of TFF1 and H. pylori with purified samples of animal and human mucins [65] detected a remarkable association between the affinities of TFF1 and H. pylori for different gastric mucin preparations (Spearman's rho $=0.81 ; p=0.002$ ). Characterisation of the accessible saccharide lectin affinities in the mucin preparations favoured by TFF1 indicated that there was a preferential interaction with terminal non-reducing $\alpha$ - or $\beta$-linked $\mathrm{N}$-acetyl-d-glucosamine or $\alpha-(2,3)$-linked sialic acid or Gal-3- $\mathrm{SO}_{4}{ }^{2-}$. If a direct interaction with these saccharides, which were not tested in the earlier study [60], was to be demonstrated, it would establish that TFF1 is able to interact with a small subset of saccharides.

The demonstration that TFF1 interacts with specific carbohydrates of H. pylori RF-LPS begs the question, with which part of TFF1 do H. pylori interact? TFF1 is an exceptionally highly charged small acidic protein with a pI of 3.94 [31]. It has, however, a region between the second and third loops of its mature, folded trefoil domain (Figure 3A) that consists largely of solvent-accessible, hydrophobic residues and includes the aromatic residues Phe19, Pro20, Pro42, and Trp43 [66]. It has been suggested that this small hydrophobic patch, which has a cleft-like shape and is present in all trefoil domains, is a potential binding pocket for an oligosaccharide or forms part of a protein binding site that includes hydrophobic interaction with side-chains of aromatic residues such as proline or tryptophan. Comparison of the structures of the hydrophobic clefts present in the four human trefoil domains, confirms that conserved residues either form the core of the domain or are located around the cleft [29]. Formed mainly from the peptide backbone, the only side chains that contribute are those of the absolutely conserved Pro20, Pro42 and Trp43 in TFF1 and the semi-conserved Phe19 of TFF1 that is replaced by a tyrosine in TFF2's second trefoil domain and in TFF3 $[29,66]$. Several residues that flank 
these aromatic amino acid residues and have conserved properties provide additional interactions that could confer specificity to interaction with a trefoil factor ligand or receptor (Figure 3A). The presence of Gly21 on the edge of the TFF1 hydrophobic cleft, and glycine residues in the equivalent positions in both TFF2 trefoil domains, is likely to facilitate access of any ligand whereas the presence of His 25 in the equivalent positon in TFF3 is likely to impede access. Notably, a further difference among these potential binding pockets in TFF1 and TFF3 is that, whereas in TFF1 the cleft is narrow, $6 \AA$, in TFF3 it is much wider, 11-12 $\AA$, and has a more shelf-like structure. Should this groove prove to be the site of interaction of TFF1 with H. pylori RF-LPS, it is perhaps not surprising that although the TFF3 molecule is able to interact, its affinity is reduced because its binding pocket has incomplete sequence conservation with and is much larger than the TFF1 binding pocket $[29,67]$.
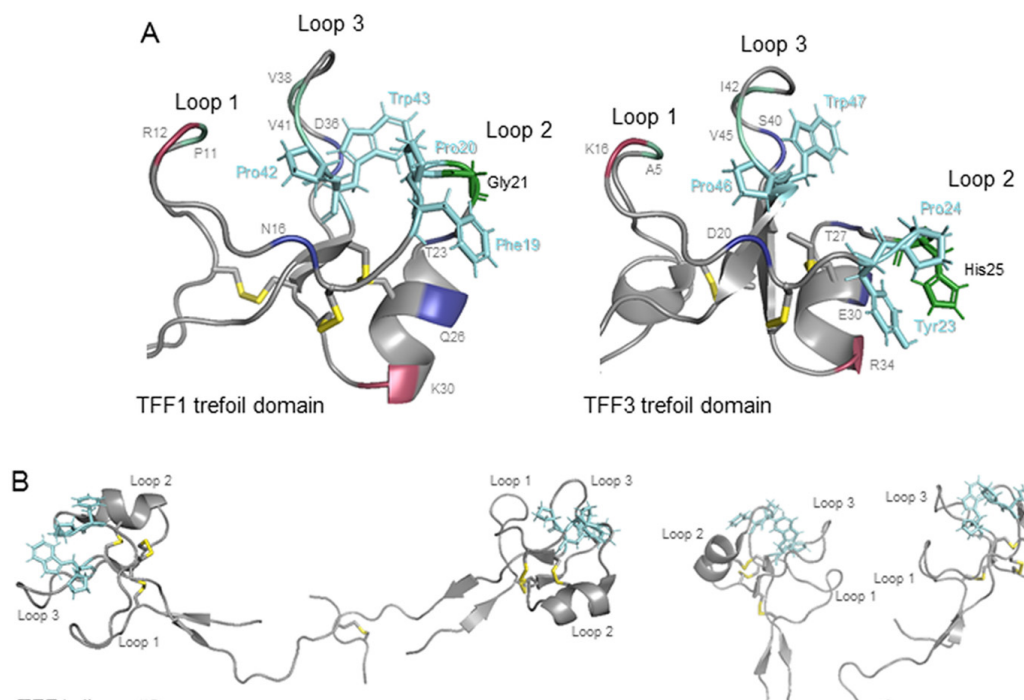

TFF1 dimer \#2
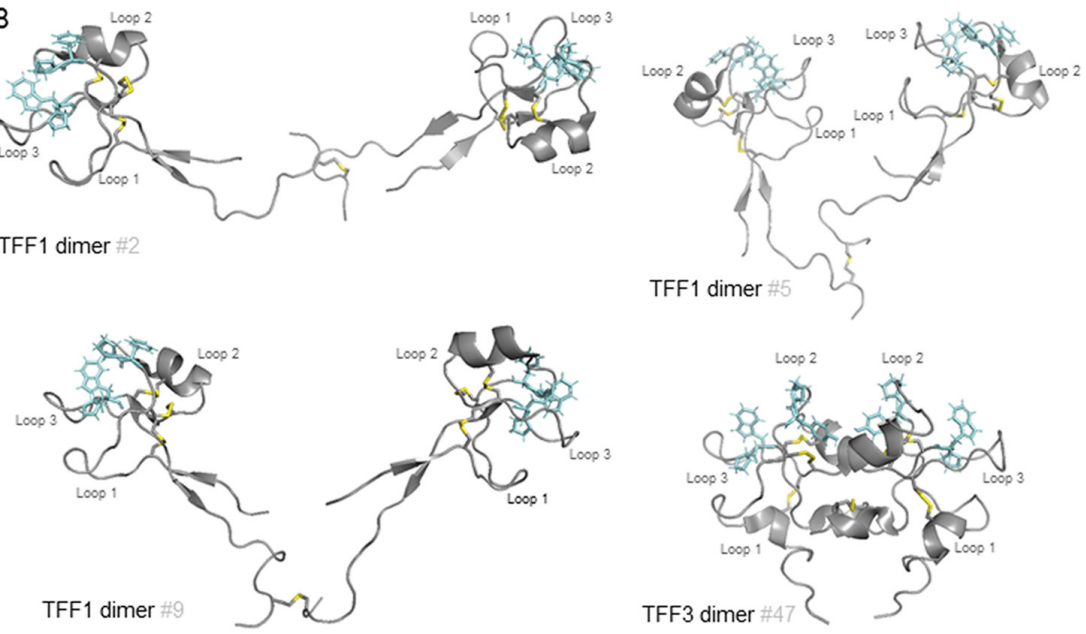

Figure 3. Hydrophobic surfaces of TFF1 and TFF3. Representations of the backbones of the TFF1 and TFF3 trefoil domains $[57,60]$ (A) and TFF1 and TFF3 dimers [58,59] (B) are shown. The intramolecular and intermolecular disulphide bonds are shown and coloured yellow. The three fully conserved solvent accessible residues, Pro 20, Pro42 and Trp43 in TFF1, and one semi-conserved solvent accessible residue, Phe19 in TFF1, in loops 2 and 3 that form a continuous hydrophobic patch postulated to interact with a saccharide or aromatic amino acid sidechain between loops 2 and 3 are shown in stick representation and are coloured cyan $(\mathbf{A}, \mathbf{B})$. The backbones of the surface residues with conserved features that surround this patch are indicated in single letter code (A). Of these, the hydrophobic residues, Pro11 (P11), Val38 (V38) and Val41 (V41) in TFF1, are coloured pale green, the hydrogen bond donor, Arg12 (R12) is coloured raspberry red and the hydrogen bond acceptors, Asn16 (N16), Thr23 (T23), Gln26 (Q26) and Asp36 (D36) in TFF1, are coloured deep blue. Two other well-conserved residues on the edge of the hydrophobic patch are indicated. A positively charged residue, Lys30 (K30) in TFF1, is coloured raspberry red. The small Gly21 in TFF1 that would facilitate access to the hydrophobic cleft and the corresponding His 25 residue of TFF3 proposed to impede access are shown in stick representation and are coloured forest green (A). Three of the solution NMR structures of the TFF1 dimer, \#2, \#5 and \#9 and one of the TFF3 dimers (\#47), are shown with the first monomer unit on the left-hand side. 
The TFF1 dimer that interacts preferentially with H. pylori RF-LPS has two of these small hydrophobic patches one on each monomer unit [68]. The higher affinity of the TFF1 dimer than the TFF1 monomer for H. pylori may indicate that the same binding surface from each monomer unit is involved in the interaction with $H$. pylori. Alternatively, different surfaces may be required and the spatial accessibility or physical proximity is provided best by two covalently bound units. The two trefoil domains are connected by a flexible region that comprises the amino- and carboxy-termini of each monomeric unit [68]. The distance between the $\alpha$ carbons of the Pro20 residues of the putative binding surface varied between 36 and $73 \AA$ and the spatial orientations of the two monomer units were divergent in the different molecular structures; the two trefoil domains did not adopt a fixed orientation with respect to each other (Figure 3B). In the structure on the top left, \#2, the TFF1 monomer units were in the same orientation with both hydrophobic surfaces on the same face of the molecule orientated towards the viewer. In the structure on the top right, \#5, the TFF1 monomer units are much closer together and are in opposite orientations with the two loop 1s proximate and with the first hydrophobic surface orientated away from the viewer and the second towards the viewer. In the structure on the bottom left, \#9, the monomer units are again in opposite orientations but with the two loop 2s proximate and with the first hydrophobic surface orientated towards the viewer and the second away from the viewer. In contrast, in the TFF3 dimer structure, \#47, the monomer units were a relatively fixed distance apart of 13-19 A between the $\alpha$ carbons of the Pro24 residues, and were always in the same opposite orientation with the two loop 2s proximate and with both hydrophobic surfaces on the same face of the molecule but facing in opposite directions. Thus, the distance between and spatial orientations of the monomer units in the TFF1 dimer have inherent flexibility and adaptability, at least between $\mathrm{pH} 5.6$ and 7.6 , that is not provided by the TFF3 dimer $[67,68]$. This versatility might facilitate crosslinking of $H$. pylori to other molecules such as mucins.

\section{The Interaction of H. pylori with TFF1 Explains Site-Specific Localisation of the Bacteria Within the Stomach}

The unique adaptation of $H$. pylori to the harsh acidic environment of the stomach is facilitated by its expression of a urease that assists neutralisation of its microenvironment [21]. However, H. pylori are not localised predominantly in the gastric lumen nor are they found in significant concentrations in association with gastric mucosal surface epithelial cells. Rather, $H$. pylori colonise the adherent mucus gel layer. They burrow, with the assistance of their flagella into the mucus and down into a preferred layer by chemotaxis stimulated by avoidance of high $\mathrm{H}^{+}$concentrations [22,69]. The specific tropism of $H$. pylori for the inner layer of the adherent mucus gel layer led us to investigate the $\mathrm{pH}$ dependence of the TFF1 dimer interaction with H. pylori RF-LPS. The interaction in solution was significantly greater at $\mathrm{pH} 5.0$ and 6.0 than at either $\mathrm{pH} 4.0$ or 7.0 . The $\mathrm{pH}$ preference at $\mathrm{pH} 5.0$ and 6.0 was investigated by analysis of the interaction of TFF1 dimer with fractionated and immobilised H. pylori RF-LPS; interaction was slightly higher at $\mathrm{pH} 6.0$ than $\mathrm{pH}$ 5.0. Helicobacter pylori colonise a region of the $100 \mu \mathrm{m}$ thick adherent mucus gel layer $0-25 \mu \mathrm{m}$ above the epithelium in an animal model [22]. The optimum $\mathrm{pH}$ for the interaction between TFF1 dimer and H. pylori RF-LPS suggests that this interaction may facilitate the localisation of $\mathrm{H}$. pylori in the adherent mucus gel layer a little above the junction between the epithelial layer and the mucus layer (Figure 4). The optimum binding for TFF3 homodimer to RF-LPS was pH 7.0 and was considerably less than that observed for TFF1 at pH 5.0-6.0 [60]. It is plausible that H. pylori could bind to TFF3 in the intestine at pH 7.0. However, this interaction would likely occur at the intestinal lumen which would result in removal of the bacteria due to mucus turnover. Such an interaction could be one of the reasons why we do not see H. pylori in the intestine. 


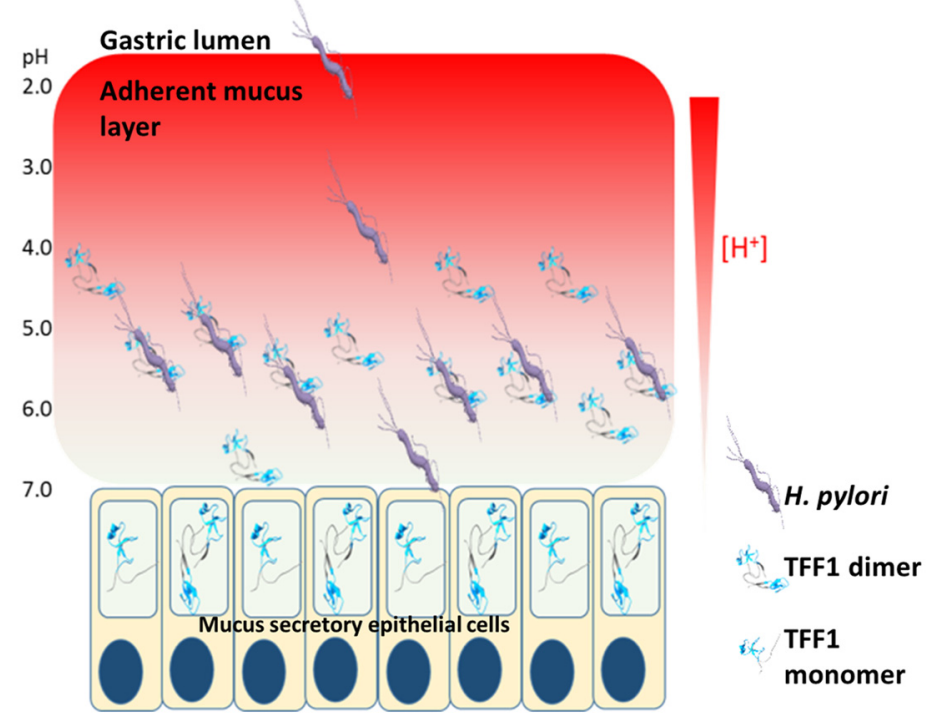

Figure 4. Potential biological effect of $H$. pylori interaction with TFF1. TFF1 is localised within mucous granules in mucus-secreting cells and is secreted from the cells into the adherent mucus layer. TFF1 is concentrated close to the epithelial surface at the higher $\mathrm{pH}$ end of the $\mathrm{pH}$ gradient. Upon entering the stomach, $H$. pylori travel through the mucus layer to escape the acidic environment present in the gastric lumen. H. pylori reside in a niche close to the gastric epithelium where the $\mathrm{pH}$ is near neutral. Binding of H. pylori to TFF1 occurs best at pH 5.0-6.0 and may anchor H. pylori deep in the mucus layer close to the epithelial cells. This interaction may limit the number of organisms that reach and interact with the epithelial cells, thus reducing the inflammatory response.

We assessed if $H$. pylori binding to TFF1 could promote mucus colonisation [70]. The HT29-MTX-E12 cell line is a subclone of the colorectal adenocarcinoma cell line HT29-MTX, that forms tight junctions and produces an adherent mucus layer when grown on Transwell filters [71]. Production of the secreted mucin MUC5AC and cell surface expression of the membrane-bound mucin MUC1 was demonstrated by immunofluorescence. A few cells produced the intestinal mucin MUC2. The cells produced all three human trefoil factors, but the immunoreaction for TFF2 was weaker than for TFF1 and TFF3. The extracellular adherent mucus gel layer contained MUC5AC, TFF1 and TFF3 [70]. Helicobacter pylori infected the cells and formed discrete clusters within the mucus layer in close association with TFF1. An isogenic mutant of H. pylori with a truncated LPS core colonised the HT29-MTX-E12 mucus layer less well than the wild-type parent strain indicating that the full length core-oligosacchairde is required for interaction with TFF1. Furthermore, pre-incubation of cells with LPS from the wild-type strain but not with LPS from the mutant strain reduced colonization [70]. These results demonstrate that the interaction of the core oligosaccharide of H. pylori LPS with TFF1 can promote colonisation of mucus. Interestingly, commensal E. coli strains engineered to produce recombinant fimbriae that express fusion trefoil factor proteins at their tips bound more mucin than $E$. coli transfected with an empty vector [72], which is further evidence that TFF1 present on the surface of bacteria can promote binding to mucin.

Analysis of different clinical isolates found that there was considerable diversity in both the level of glycosylation and the length of the fucosylated O-antigen chains among strains isolated from either the same or different individuals [73]. Of note, reduced Lewis antigen expression was found when isolates were grown at $\mathrm{pH} 5.0$ compared to growth at $\mathrm{pH} 7.0$ [73]. Reduced presence of SF-LPs would expose more RF-LPS on the bacterial surface and would enhance the interaction of $H$. pylori with TFF1. We hypothesise that the interaction of H. pylori with TFF1 that is favoured at $\mathrm{pH}$ 5.0-6.0 serves to locate H. pylori in the gastric mucus layer close to the epithelium rather than at the epithelial surface. This restricted localisation could limit the number of $H$. pylori that interact with epithelial cells and, thus, reduce host signalling events that cause inflammation (Figure 4). In 
support of this hypothesis, it has been shown that $H$. pylori strains isolated from asymptomatic, infected individuals tend to express lower molecular mass RF-LPS than those isolated from individuals with severe gastroduodenal disease [73-75]. In addition, $H$. pylori infection of TFF1-null mice causes more severe gastric inflammation than infection of wild-type mice [76], which suggests that an increased number of organisms may interact with the epithelial cells if TFF1 is absent from the gastric mucus than if it is present.

Funding: We would like to acknowledge the funding agencies that supported work from our groups reviewed in this manuscript. This research was funded by grants from The National Childrens Research Center, Dublin, Ireland, Science Foundation Ireland, grant number 08/SRC/B1393, The Irish Research Council for Science Engineering and Technology, GOI Postgraduate Scholarship Scheme to Ciara Dunne and by University College Dublin, grant number SF1700, The Wellcome Trust, The Medical Research Council, Cancer Research UK, Cancer Research Campaign and the Newcastle University Hospitals' Special Trustees.

Conflicts of Interest: The authors declare no conflict of interest.

\section{References}

1. Hooi, J.K.Y.; Lai, W.Y.; Ng, W.K.; Suen, M.M.Y.; Underwood, F.E.; Tanyingoh, D.; Malfertheiner, P.; Graham, D.Y.; Wong, V.W.S.; Wu, J.C.Y.; et al. Global prevalence of Helicobacter pylori infection: Systematic review and meta-analysis. Gastroenterology 2017, 153, 420-429. [CrossRef] [PubMed]

2. Drumm, B.; Perez-Perez, G.I.; Blaser, M.J.; Sherman, P.M. Intrafamilial clustering of Helicobacter pylori infection. N. Engl. J. Med. 1990, 322, 359-363. [CrossRef] [PubMed]

3. Rowland, M.; Daly, L.; Vaughan, M.; Higgins, A.; Bourke, B.; Drumm, B. Age-specific incidence of Helicobacter pylori. Gastroenterology 2006, 130, 65-72. [CrossRef] [PubMed]

4. Blanchard, T.G.; Czinn, S.J. Identification of Helicobacter pylori and the evolution of an efficacious childhood vaccine to protect against gastritis and peptic ulcer disease. Pediatr. Res. 2017, 81, 170-176. [CrossRef] [PubMed]

5. McColl, K.E. Clinical practice. Helicobacter pylori infection. N. Engl. J. Med. 2010, 362, 1597-1604. [PubMed]

6. Leow, A.H.; Lim, Y.Y.; Liew, W.C.; Goh, K.L. Time trends in upper gastrointestinal diseases and Helicobacter pylori infection in a multiracial asian population-a 20-year experience over three time periods. Aliment. Pharmacol. Ther. 2016, 43, 831-837. [CrossRef]

7. Sonnenberg, A. Review article: Historic changes of Helicobacter pylori-associated diseases. Aliment. Pharmacol. Ther. 2013, 38, 329-342. [CrossRef]

8. Plummer, M.; Franceschi, S.; Vignat, J.; Forman, D.; de Martel, C. Global burden of gastric cancer attributable to Helicobacter pylori. Int. J. Cancer 2015, 136, 487-490. [CrossRef]

9. Howitt, M.R.; Lee, J.Y.; Lertsethtakarn, P.; Vogelmann, R.; Joubert, L.M.; Ottemann, K.M.; Amieva, M.R. ChePep controls Helicobacter pylori infection of the gastric glands and chemotaxis in the Epsilonproteobacteria. MBio 2011, 2. [CrossRef]

10. Keilberg, D.; Zavros, Y.; Shepherd, B.; Salama, N.R.; Ottemann, K.M. Spatial and temporal shifts in bacterial biogeography and gland occupation during the development of a chronic infection. MBio 2016, 7. [CrossRef]

11. Fung, C.; Tan, S.; Nakajima, M.; Skoog, E.C.; Camarillo-Guerrero, L.F.; Klein, J.A.; Lawley, T.D.; Solnick, J.V.; Fukami, T.; Amieva, M.R. High-resolution mapping reveals that microniches in the gastric glands control Helicobacter pylori colonization of the stomach. PLoS Biol. 2019, 17, e3000231. [CrossRef] [PubMed]

12. Hessey, S.J.; Spencer, J.; Wyatt, J.I.; Sobala, G.; Rathbone, B.J.; Axon, A.T.; Dixon, M.F. Bacterial adhesion and disease activity in Helicobacter associated chronic gastritis. Gut 1990, 31, 134-138. [CrossRef] [PubMed]

13. Hidaka, E.; Ota, H.; Hidaka, H.; Hayama, M.; Matsuzawa, K.; Akamatsu, T.; Nakayama, J.; Katsuyama, T. Helicobacter pylori and two ultrastructurally distinct layers of gastric mucous cell mucins in the surface mucous gel layer. Gut 2001, 49, 474-480. [CrossRef] [PubMed]

14. Wyatt, J.I.; Rathbone, B.J.; Sobala, G.M.; Shallcross, T.; Heatley, R.V.; Axon, A.T.; Dixon, M.F. Gastric epithelium in the duodenum: Its association with Helicobacter pylori and inflammation. J. Clin. Pathol 1990, 43, 981-986. [CrossRef] [PubMed]

15. Van de Bovenkamp, J.H.; Mahdavi, J.; Korteland-Van Male, A.M.; Buller, H.A.; Einerhand, A.W.; Boren, T.; Dekker, J. The muc5ac glycoprotein is the primary receptor for Helicobacter pylori in the human stomach. Helicobacter 2003, 8, 521-532. [CrossRef] [PubMed] 
16. Van den Brink, G.R.; Tytgat, K.M.; Van der Hulst, R.W.; Van der Loos, C.M.; Einerhand, A.W.; Buller, H.A.; Dekker, J.H. pylori colocalises with MUC5AC in the human stomach. Gut 2000, 46, 601-607. [CrossRef]

17. Genta, R.M.; Gurer, I.E.; Graham, D.Y.; Krishnan, B.; Segura, A.M.; Gutierrez, O.; Kim, J.G.; Burchette, J.L., Jr. Adherence of Helicobacter pylori to areas of incomplete intestinal metaplasia in the gastric mucosa. Gastroenterology 1996, 111, 1206-1211. [CrossRef] [PubMed]

18. Teixeira, A.; David, L.; Reis, C.A.; Costa, J.; Sobrinho-Simoes, M. Expression of mucins (MUC1, MUC2, MUC5AC, and MUC6) and type 1 Lewis antigens in cases with and without Helicobacter pylori colonization in metaplastic glands of the human stomach. J. Pathol. 2002, 197, 37-43. [CrossRef]

19. Johansson, M.E.; Sjovall, H.; Hansson, G.C. The gastrointestinal mucus system in health and disease. Nat. Rev. Gastroenterol. Hepatol. 2013, 10, 352-361. [CrossRef]

20. Lewis, O.L.; Keener, J.P.; Fogelson, A.L. A physics-based model for maintenance of the ph gradient in the gastric mucus layer. Am. J. Physiol. Gastrointest. Liver Physiol. 2017, 313, G599-G612. [CrossRef]

21. Clyne, M.; Labigne, A.; Drumm, B. Helicobacter pylori requires an acidic environment to survive in the presence of urea. Infect. Immun. 1995, 63, 1669-1673. [PubMed]

22. Schreiber, S.; Konradt, M.; Groll, C.; Scheid, P.; Hanauer, G.; Werling, H.O.; Josenhans, C.; Suerbaum, S. The spatial orientation of Helicobacter pylori in the gastric mucus. Proc. Natl. Acad. Sci. USA 2004, 101, 5024-5029. [CrossRef] [PubMed]

23. Ilver, D.; Arnqvist, A.; Ogren, J.; Frick, I.M.; Kersulyte, D.; Incecik, E.T.; Berg, D.E.; Covacci, A.; Engstrand, L.; Boren, T. Helicobacter pylori adhesin binding fucosylated histo-blood group antigens revealed by retagging. Science 1998, 279, 373-377. [CrossRef] [PubMed]

24. Jin, C.; Barone, A.; Boren, T.; Teneberg, S. Helicobacter pylori-binding nonacid glycosphingolipids in the human stomach. J. Biol. Chem. 2018, 293, 17248-17266. [CrossRef] [PubMed]

25. Mahdavi, J.; Sonden, B.; Hurtig, M.; Olfat, F.O.; Forsberg, L.; Roche, N.; Angstrom, J.; Larsson, T.; Teneberg, S.; Karlsson, K.A.; et al. Helicobacter pylori SabA adhesin in persistent infection and chronic inflammation. Science 2002, 297, 573-578. [CrossRef]

26. Rossez, Y.; Gosset, P.; Boneca, I.G.; Magalhaes, A.; Ecobichon, C.; Reis, C.A.; Cieniewski-Bernard, C.; Joncquel Chevalier Curt, M.; Leonard, R.; Maes, E.; et al. The lacdinac-specific adhesin LabA mediates adhesion of Helicobacter pylori to human gastric mucosa. J. Infect. Dis. 2014, 210, 1286-1295. [CrossRef]

27. May, F.E.; Westley, B.R. Trefoil proteins: Their role in normal and malignant cells. J. Pathol 1997, $183,4-7$. [CrossRef]

28. Thim, L.; Madsen, F.; Poulsen, S.S. Effect of trefoil factors on the viscoelastic properties of mucus gels. Eur. J. Clin. Investig. 2002, 32, 519-527. [CrossRef]

29. Thim, L.; May, F.E. Structure of mammalian trefoil factors and functional insights. Cell Mol. Life Sci. 2005, 62, 2956-2973. [CrossRef]

30. Chadwick, M.P.; Westley, B.R.; May, F.E. Homodimerization and hetero-oligomerization of the single-domain trefoil protein pNR-2/pS2 through cysteine 58. Biochem. J. 1997, 327(Pt. 1), 117-123. [CrossRef]

31. May, F.E.; Church, S.T.; Major, S.; Westley, B.R. The closely related estrogen-regulated trefoil proteins TFF1 and TFF3 have markedly different hydrodynamic properties, overall charge, and distribution of surface charge. Biochemistry 2003, 42, 8250-8259. [CrossRef] [PubMed]

32. Masiakowski, P.; Breathnach, R.; Bloch, J.; Gannon, F.; Krust, A.; Chambon, P. Cloning of cDNA sequences of hormone-regulated genes from the MCF-7 human breast cancer cell line. Nucleic Acids Res. 1982, 10, 7895-7903. [CrossRef] [PubMed]

33. May, F.E.; Westley, B.R. Cloning of estrogen-regulated messenger RNA sequences from human breast cancer cells. Cancer Res. 1986, 46, 6034-6040. [PubMed]

34. Jorgensen, K.H.; Thim, L.; Jacobsen, H.E. Pancreatic spasmolytic polypeptide (pSP): I. Preparation and initial chemical characterization of a new polypeptide from porcine pancreas. Regul. Pept. 1982, 3, 207-219. [CrossRef]

35. Suemori, S.; Lynch-Devaney, K.; Podolsky, D.K. Identification and characterization of rat intestinal trefoil factor: Tissue- and cell-specific member of the trefoil protein family. Proc. Natl. Acad. Sci. USA 1991, 88, 11017-11021. [CrossRef] [PubMed]

36. Madsen, J.; Nielsen, O.; Tornoe, I.; Thim, L.; Holmskov, U. Tissue localization of human trefoil factors 1, 2, and 3. J. Histochem. Cytochem. 2007, 55, 505-513. [CrossRef] [PubMed] 
37. Dos Santos Silva, E.; Ulrich, M.; Doring, G.; Botzenhart, K.; Gott, P. Trefoil factor family domain peptides in the human respiratory tract. J. Pathol. 2000, 190, 133-142. [CrossRef]

38. Ahmed, A.R.H.; Griffiths, A.B.; Tilby, M.T.; Westley, B.R.; May, F.E.B. TFF3 is a normal breast epithelial protein and is associated with differentiated phenotype in early breast cancer but predisposes to invasion and metastasis in advanced disease. Am. J. Pathol. 2012, 180, 904-916. [CrossRef]

39. Piggott, N.H.; Henry, J.A.; May, F.E.; Westley, B.R. Antipeptide antibodies against the pNR-2 oestrogen-regulated protein of human breast cancer cells and detection of pNR-2 expression in normal tissues by immunohistochemistry. J. Pathol. 1991, 163, 95-104. [CrossRef]

40. May, F.E.B.; Westley, B.R. TFF3 is a valuable predictive biomarker of endocrine response in metastatic breast cancer. Endocr.-Relat. Cancer 2015, 22, 465-479. [CrossRef]

41. May, F.E.; Semple, J.I.; Prest, S.J.; Westley, B.R. Expression and motogenic activity of TFF2 in human breast cancer cells. Peptides 2004, 25, 865-872. [CrossRef] [PubMed]

42. Ruchaud-Sparagano, M.H.; Westley, B.R.; May, F.E. The trefoil protein TFF1 is bound to MUC5AC in human gastric mucosa. Cell. Mol. Life Sci. 2004, 61, 1946-1954. [CrossRef] [PubMed]

43. Hanby, A.M.; Poulsom, R.; Elia, G.; Singh, S.; Longcroft, J.M.; Wright, N.A. The expression of the trefoil peptides pS2 and human spasmolytic polypeptide (hSP) in 'gastric metaplasia' of the proximal duodenum: Implications for the nature of 'gastric metaplasia'. J. Pathol. 1993, 169, 355-360. [CrossRef] [PubMed]

44. May, F.E.; Griffin, S.M.; Westley, B.R. The trefoil factor interacting protein TFIZ1 binds the trefoil protein TFF1 preferentially in normal gastric mucosal cells but the co-expression of these proteins is deregulated in gastric cancer. Int. J. Biochem. Cell. Biol. 2009, 41, 632-640. [CrossRef] [PubMed]

45. Newton, J.L.; Allen, A.; Westley, B.R.; May, F.E. The human trefoil peptide, TFF1, is present in different molecular forms that are intimately associated with mucus in normal stomach. Gut 2000, 46, 312-320. [CrossRef] [PubMed]

46. Westley, B.R.; Griffin, S.M.; May, F.E. Interaction between TFF1, a gastric tumor suppressor trefoil protein, and TFIZ1, a brichos domain-containing protein with homology to sp-c. Biochemistry 2005, 44, 7967-7975. [CrossRef] [PubMed]

47. Menheniott, T.R.; Peterson, A.J.; O'Connor, L.; Lee, K.S.; Kalantzis, A.; Kondova, I.; Bontrop, R.E.; Bell, K.M.; Giraud, A.S. A novel gastrokine, GKN3, marks gastric atrophy and shows evidence of adaptive gene loss in humans. Gastroenterology 2010, 138, 1823-1835. [CrossRef] [PubMed]

48. Clyne, M.; Dillon, P.; Daly, S.; O’Kennedy, R.; May, F.E.; Westley, B.R.; Drumm, B. Helicobacter pylori interacts with the human single-domain trefoil protein TFF1. Proc. Natl. Acad. Sci. USA 2004, 101, 7409-7414. [CrossRef]

49. Jonsson, U.; Fagerstam, L.; Ivarsson, B.; Johnsson, B.; Karlsson, R.; Lundh, K.; Lofas, S.; Persson, B.; Roos, H.; Ronnberg, I.; et al. Real-time biospecific interaction analysis using surface plasmon resonance and a sensor chip technology. Biotechniques 1991, 11, 620-627.

50. Josenhans, C.; Labigne, A.; Suerbaum, S. Comparative ultrastructural and functional studies of Helicobacter pylori and Helicobacter mustelae flagellin mutants: Both flagellin subunits, FlaA and FlaB, are necessary for full motility in Helicobacter species. J. Bacteriol. 1995, 177, 3010-3020. [CrossRef]

51. Aspinall, G.O.; Monteiro, M.A. Lipopolysaccharides of Helicobacter pylori strains P466 and MO19: Structures of the $\mathrm{O}$ antigen and core oligosaccharide regions. Biochemistry 1996, 35, 2498-2504. [CrossRef]

52. Aspinall, G.O.; Monteiro, M.A.; Pang, H.; Walsh, E.J.; Moran, A.P. Lipopolysaccharide of the Helicobacter pylori type strain NCTC 11637 (ATCC 43504): Structure of the o antigen chain and core oligosaccharide regions. Biochemistry 1996, 35, 2489-2497. [CrossRef] [PubMed]

53. Monteiro, M.A.; Chan, K.H.; Rasko, D.A.; Taylor, D.E.; Zheng, P.Y.; Appelmelk, B.J.; Wirth, H.P.; Yang, M.; Blaser, M.J.; Hynes, S.O.; et al. Simultaneous expression of type 1 and type 2 Lewis blood group antigens by Helicobacter pylori lipopolysaccharides. Molecular mimicry between $H$. pylori lipopolysaccharides and human gastric epithelial cell surface glycoforms. J. Biol. Chem. 1998, 273, 11533-11543. [CrossRef] [PubMed]

54. Monteiro, M.A.; Rasko, D.; Taylor, D.E.; Perry, M.B. Glucosylated n-acetyllactosamine o-antigen chain in the lipopolysaccharide from Helicobacter pylori strainUA861. Glycobiology 1998, 8, 107-112. [CrossRef] [PubMed]

55. Moran, A.P.; Lindner, B.; Walsh, E.J. Structural characterization of the Lipid A component of Helicobacter pylori rough- and smooth-form lipopolysaccharides. J. Bacteriol. 1997, 179, 6453-6463. [CrossRef] [PubMed] 
56. Cullen, T.W.; Giles, D.K.; Wolf, L.N.; Ecobichon, C.; Boneca, I.G.; Trent, M.S. Helicobacter pylori versus the host: Remodeling of the bacterial outer membrane is required for survival in the gastric mucosa. PLoS Pathog. 2011, 7, e1002454. [CrossRef] [PubMed]

57. Moran, A.P. Relevance of fucosylation and Lewis antigen expression in the bacterial gastroduodenal pathogen Helicobacter pylori. Carbohydr. Res. 2008, 343, 1952-1965. [CrossRef]

58. Edwards, N.J.; Monteiro, M.A.; Faller, G.; Walsh, E.J.; Moran, A.P.; Roberts, I.S.; High, N.J. Lewis x structures in the $\mathrm{O}$ antigen side-chain promote adhesion of Helicobacter pylori to the gastric epithelium. Mol. Microbiol. 2000, 35, 1530-1539. [CrossRef]

59. Li, H.; Liao, T.; Debowski, A.W.; Tang, H.; Nilsson, H.O.; Stubbs, K.A.; Marshall, B.J.; Benghezal, M. Lipopolysaccharide structure and biosynthesis in Helicobacter pylori. Helicobacter 2016, 21, 445-461. [CrossRef]

60. Reeves, E.P.; Ali, T.; Leonard, P.; Hearty, S.; O’Kennedy, R.; May, F.E.; Westley, B.R.; Josenhans, C.; Rust, M.; Suerbaum, S.; et al. Helicobacter pylori lipopolysaccharide interacts with TFF1 in a pH-dependent manner. Gastroenterology 2008, 135, 2043-2054, 2054 e2041-e2042. [CrossRef]

61. Moran, A.P.; Helander, I.M.; Kosunen, T.U. Compositional analysis of Helicobacter pylori rough-form lipopolysaccharides. J. Bacteriol. 1992, 174, 1370-1377. [CrossRef] [PubMed]

62. Leker, K.; Lozano-Pope, I.; Bandyopadhyay, K.; Choudhury, B.P.; Obonyo, M. Comparison of lipopolysaccharides composition of two different strains of Helicobacter pylori. BMC Microbiol. 2017, 17, 226. [CrossRef] [PubMed]

63. Lee, A.; O’Rourke, J.; de Ungria, M.C.; Robertson, B.; Daskalopoulos, G.; Dixon, M.F. A standardized mouse model of Helicobacter pylori infection: Introducing the Sydney strain. Gastroenterology 1997, 112, 1386-1397. [CrossRef]

64. Covacci, A.; Censini, S.; Bugnoli, M.; Petracca, R.; Burroni, D.; Macchia, G.; Massone, A.; Papini, E.; Xiang, Z.; Figura, N.; et al. Molecular characterization of the 128-kda immunodominant antigen of Helicobacter pylori associated with cytotoxicity and duodenal ulcer. Proc. Natl. Acad. Sci. USA 1993, 90, 5791-5795. [CrossRef] [PubMed]

65. Dunne, C.; Naughton, J.; Duggan, G.; Loughrey, C.; Kilcoyne, M.; Joshi, L.; Carrington, S.; Earley, H.; Backert, S.; Robbe Masselot, C.; et al. Binding of Helicobacter pylori to human gastric mucins correlates with binding of TFF1. Microorganisms 2018, 6, 44. [CrossRef] [PubMed]

66. Polshakov, V.I.; Williams, M.A.; Gargaro, A.R.; Frenkiel, T.A.; Westley, B.R.; Chadwick, M.P.; May, F.E.; Feeney, J. High-resolution solution structure of human pNR-2/pS2: A single trefoil motif protein. J. Mol. Biol. 1997, 267, 418-432. [CrossRef]

67. Muskett, F.W.; May, F.E.; Westley, B.R.; Feeney, J. Solution structure of the disulfide-linked dimer of human intestinal trefoil factor (TFF3): The intermolecular orientation and interactions are markedly different from those of other dimeric trefoil proteins. Biochemistry 2003, 42, 15139-15147. [CrossRef] [PubMed]

68. Williams, M.A.; Westley, B.R.; May, F.E.; Feeney, J. The solution structure of the disulphide-linked homodimer of the human trefoil protein TFF1. FEBS Lett. 2001, 493, 70-74. [CrossRef]

69. Schreiber, S.; Bucker, R.; Groll, C.; Azevedo-Vethacke, M.; Garten, D.; Scheid, P.; Friedrich, S.; Gatermann, S.; Josenhans, C.; Suerbaum, S. Rapid loss of motility of Helicobacter pylori in the gastric lumen in vivo. Infect. Immun. 2005, 73, 1584-1589. [CrossRef]

70. Dolan, B.; Naughton, J.; Tegtmeyer, N.; May, F.E.; Clyne, M. The interaction of Helicobacter pylori with the adherent mucus gel layer secreted by polarized HT29-MTX-E12 cells. PLoS ONE 2012, 7, e47300. [CrossRef]

71. Behrens, I.; Stenberg, P.; Artursson, P.; Kissel, T. Transport of lipophilic drug molecules in a new mucus-secreting cell culture model based on HT29-MTX cells. Pharm. Res. 2001, 18, 1138-1145. [CrossRef] [PubMed]

72. Duraj-Thatte, A.M.; Praveschotinunt, P.; Nash, T.R.; Ward, F.R.; Joshi, N.S. Modulating bacterial and gut mucosal interactions with engineered biofilm matrix proteins. Sci. Rep. 2018, 8, 3475. [CrossRef] [PubMed]

73. Skoglund, A.; Backhed, H.K.; Nilsson, C.; Bjorkholm, B.; Normark, S.; Engstrand, L. A changing gastric environment leads to adaptation of lipopolysaccharide variants in Helicobacter pylori populations during colonization. PLoS ONE 2009, 4, e5885. [CrossRef] [PubMed]

74. Heneghan, M.A.; McCarthy, C.F.; Moran, A.P. Relationship of blood group determinants on Helicobacter pylori lipopolysaccharide with host Lewis phenotype and inflammatory response. Infect. Immun. 2000, 68, 937-941. [CrossRef] [PubMed] 
75. Rasko, D.A.; Keelan, M.; Wilson, T.J.; Taylor, D.E. Lewis antigen expression by Helicobacter pylori. J. Infect. Dis. 2001, 184, 315-321. [CrossRef] [PubMed]

76. Soutto, M.; Chen, Z.; Katsha, A.M.; Romero-Gallo, J.; Krishna, U.S.; Piazuelo, M.B.; Washington, M.K.; Peek, R.M., Jr.; Belkhiri, A.; El-Rifai, W.M. Trefoil factor 1 expression suppresses Helicobacter pylori-induced inflammation in gastric carcinogenesis. Cancer 2015, 121, 4348-4358. [CrossRef] 